American Journal of

Health, Medicine and Nursing Practice (AJHMN)

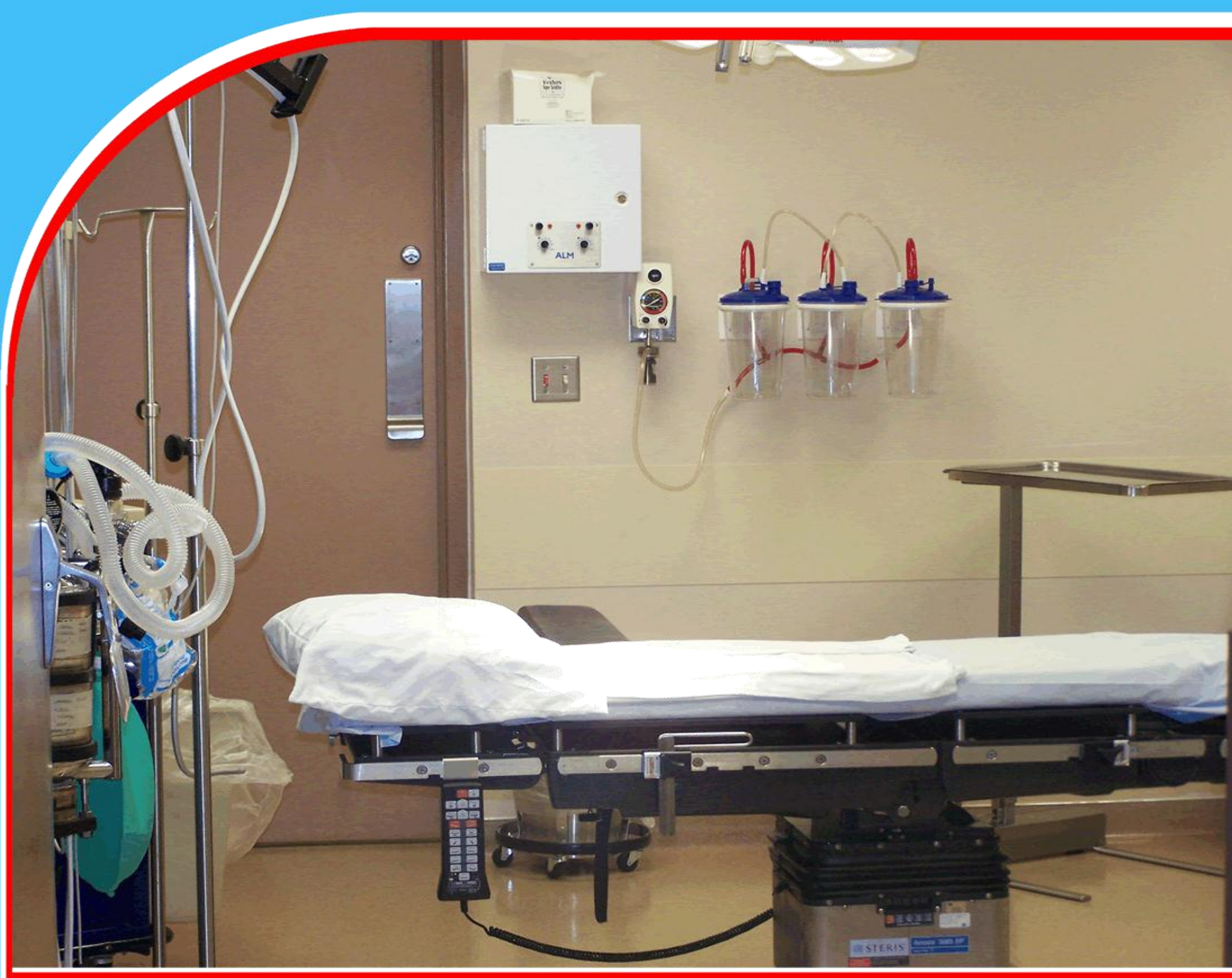

Male Subfertility; Challenges and advancement in the andrology clinic at Khyber Pakhtunkhwa, Pakistan Mir Abid Jan, Arshad, Majid Khan Kakakhel, Muhammad Hamid

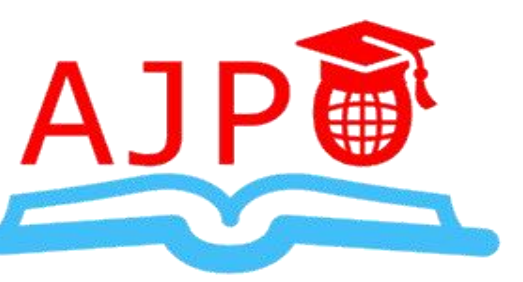




\title{
Male Subfertility; Challenges and advancement in the andrology clinic at Khyber Pakhtunkhwa, Pakistan
}

\author{
${ }^{1}$ Mir Abid Jan, ${ }^{2}$ Arshad, ${ }^{3}$ Majid Khan Kakakhel, ${ }^{4}$ Muhammad Hamid \\ 1,2,3,4 Institute of Kidney Diseases, Hayatabad Medical Complex, Peshawar \\ Corresponding Authors’ Emails: drmirabid@yahoo.com, hamidjhagra115@gmail.com
}

\begin{abstract}
Objective: This study is aimed to discuss the challenges in dealing the infertile male and advances in the treatment of male infertility.

Material and methods: The study included infertile male patients who presented to andrology outpatient as primary or secondary infertility between December 2018 and January 2021. The data detailed different aspects of challenges and advances in male infertility treatment. The data analysis was done with SPSS.

Results: Total 289 patients included, most of them (74\%) presented as primary infertility and a quarter presented as secondary infertility. The mean delay in presentation was 6.8 years which were due to treatment from non-andrologist doctors of different specialities (53.9\%), hakims $(15.2 \%)$, quacks $(13.8 \%)$, gynaecologists $(10.3 \%)$ and some were reluctant to tell their problem $(6.5 \%)$. The diagnosis was N.O.A (42.9\%), unexplained infertility $(24.2 \%)$, varicocele $(22.8 \%)$, OA $(6.2 \%)$, OAT syndrome $(2.7 \%)$ and CABVD (1\%). Different treatment option opted were vasography plus vasovasostomy or vasoepididmostomy (31.1\%), ART (23.9\%), MSV (22.8\%) and medical treatment $(22.1 \%)$. Vasography plus vasovasostomy or vasoepididmostomy and medical treatment were the available options provided. There was no ART facility and those who were counseled for referral either their unwillingness or cost resulted in a hurdle in their provision.

Conclusion: There are still a number of challenges in treating infertile men. Recently provision of medical and microsurgical treatment at andrology clinic resulted in proper treatment of a large number of infertile men who previously received treatment from un- related facilities
\end{abstract}

Keywords: Male infertility, challenges, advances, developing countries. 
American Journal of Health, Medicine and Nursing Practice

ISSN 2520-4017 (Online)

Vol.6, Issue 6, pp 8 - 14, 2021

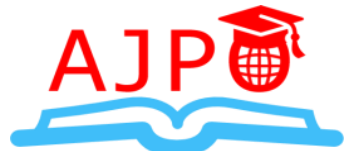

WWW.ajpojournals.org

\section{Introduction}

Subfertility is clinically defined as non-conception despite 1 year of regular unprotected intercourse [1]. Male factors for infertility contribute in about $50 \%$ and solely responsible in $20 \%$ of cases [2]. According to global statistics, infertility affects $15 \%$ of couples [3] according to other statistics it affects about 48.5 million couples [4]. This has considerable impact, as in many cultures the womanhood and manhood are defined through motherhood and fatherhood respectively. Because of lack of social security system, these parent are dependent on children and childlessness result in neglect, isolation, and domestic violence [5]. Reproduction is a natural phenomenon in living organisms, but in human being in addition to physiologic aspects, it had significant social and psychological impact on the couple. This makes the reproduction and fertility as one of the goal of marriage. Among stressful events of life, infertility is one of the most negative events which is considered almost equal to death of child or spouse [6].

The management of male subfertility dramatically improved due to advances in the micro surgical techniques and assisted reproductive techniques (ART). ART in the form of IVF and ICSI allowed us to overcome even the severe form of impaired spermatogenesis, which has only few treatment option available [7]. Unfortunately there are a number of challenges with ARTs in the developing world which result in low attention towards infertility. There is still a burden of infectious diseases on the health system and poverty is still an important issue which makes the availability and cost of these expensive techniques an important concern. Another barrier is strategies of reducing fertility in recent decades both at national and international levels [8].

This study aimed to discuss the challenges in the form of patient awareness about infertility treatment, availability, affordability and willingness for the infertility treatment and recent advances in provision of microsurgical procedures.

\section{Material and methods}

This descriptive study included male married patients with primary or secondary infertility who presented to the andrology out-patient department of the institute of kidney diseases Hayatabad medical complex Peshawar Pakistan from December 2018 to Jan 2021. The data was collected on a structured proforma which detailed the age, duration of marriage, diagnosis, delay in hospital visit, reason for delay, previous treatment, current treatment option, availability, affordability and willingness for the treatment. The data initially put in excel data sheet, later on analyzed with SPSS version 20.0 .

\section{Results}

This study included 289 male patients of subfertility with mean age of 30.7 years (Std. Deviation 6.21), a minimum of 17 and maximum 42 years. These patients were from 11 different occupations, 17 districts of Khyber Pakhtunkhwa and neighbouring country of Afghanistan. The presentation as primary or secondary infertility is detailed in figure 1 . The mean duration from marriage till presentation to the andrology clinic was 6.8 years with minimum of 1 and maximum 20 years. The reasons for delayed presentation to andrology clinic are shown in figure 2 . Different forms of subfertility treatments received were medical $(n=272,94.1 \%)$ and surgical $(n=14,4.8 \%)$, while some patients had no previous treatment for subfertility $(n=3,1 \%)$. The diagnosis made in these patients are shown figure 3. Different treatment options proposed were vasography plus vasovasostomy or vasoepididmostomy $(n=90,31.1 \%)$, ART $(n=69,23.9 \%)$, MSV $(n=66,22.8 \%)$ 
and medical treatment $(n=64,22.1 \%)$. Out of these options ART was not available which accounts for $23.9 \%$ of treatment options in current study. Regarding affordability the MSV and vasovasostomy/vasoepididmostomy were the available options in the government set up, so all those offered were able to afford the cost. Of 69 patients who were counseled for ART the majority $(\mathrm{n}=51,73.9 \%)$ were not affording these costly procedures. Total 19 patients were not willing for their required treatment, these include ART $(n=9,47.3 \%)$, MSV $(n=5,26.3)$, vasovasostomy/ vasoepididmostomy $(\mathrm{n}=4,21 \%)$ and medical treatment $(\mathrm{n}=1,5.2 \%)$. By profession shopkeepers $(n=8,42.1 \%)$, drivers $(n=3,15.7 \%)$ and laborer $(n=3,15.7 \%)$ were mainly concerned and not willing for treatment.

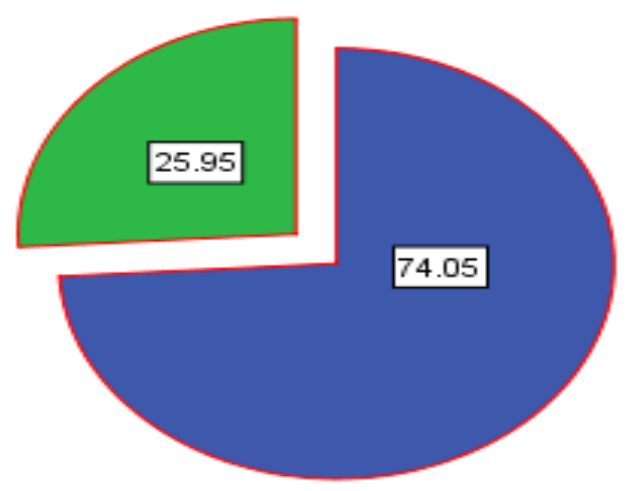

Figure 1: Prevalence of primary and secondary infertility (\%)

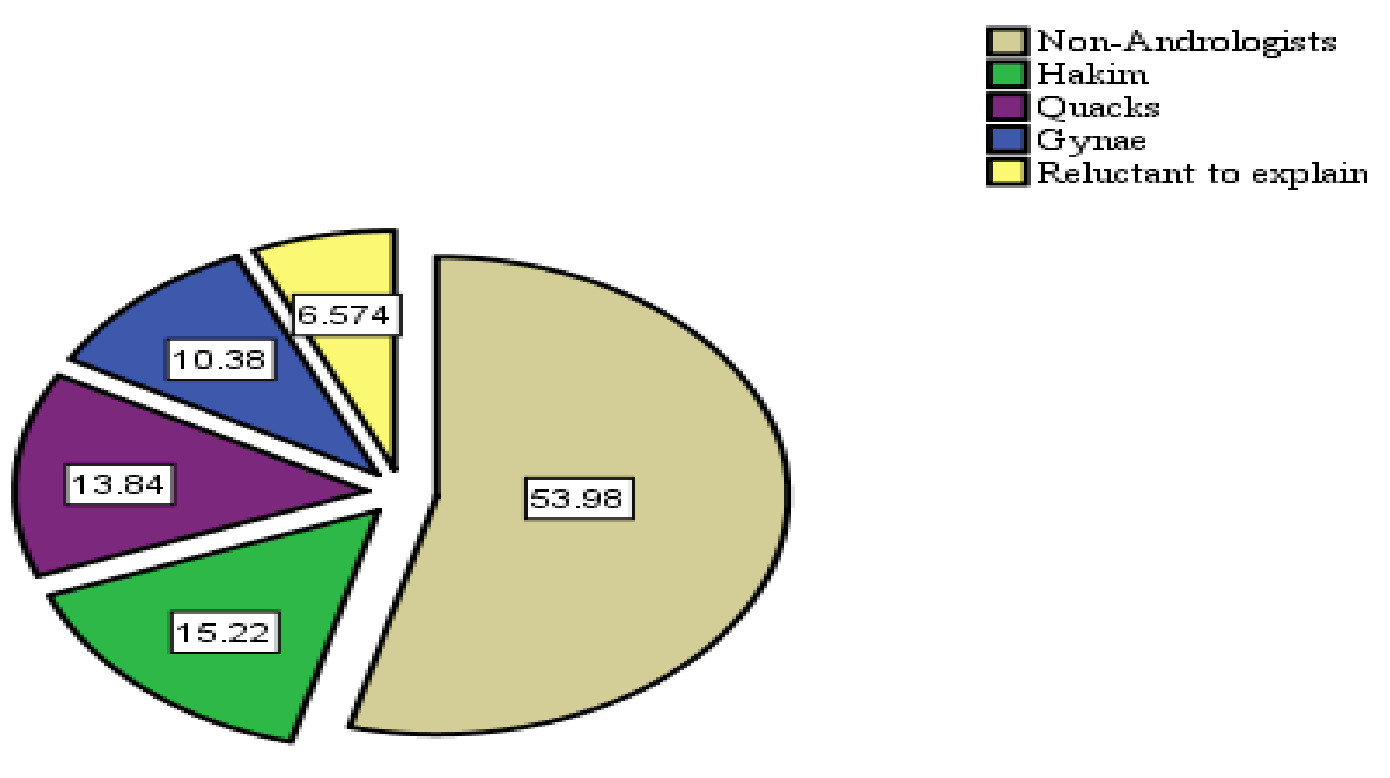

Figure 2: Reason for delayed presentation to andrology clinic (\%) 


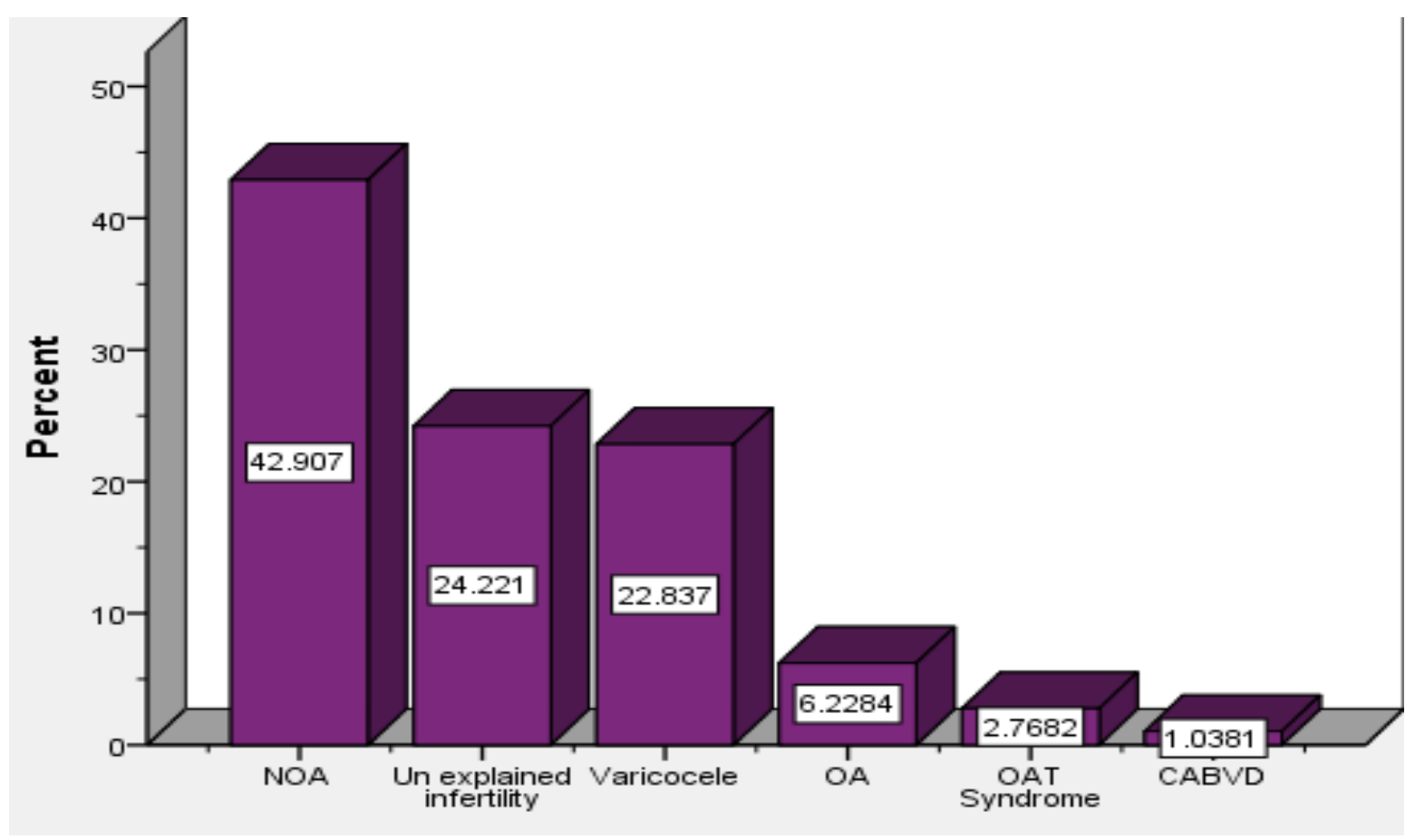

Figure 3: Diagnosis (\%)

\section{Discussion}

Global trends confirms primary infertility a more common presentation compared with secondary infertility. Similar finding noted in current study where $74 \%$ of men presented with the primary infertility, while secondary infertility accounted for $25.9 \%$. Gul et al, in their study found primary infertility in $73 \%$ and secondary infertility in $23 \%$ [9]. Öztekin et al, noticed primary infertility in $77.3 \%$ and secondary infertility in $22.7 \%$ [10]. Eric et al identified primary infertility of $52.3 \%$ [11]. Deshpande et al, showed that $57.5 \%$ of patients had primary infertility and $42.5 \%$ presented as secondary infertility [12].

In the developing world the psychosocial, economic and personal well-being is highly affected by Infertility, further this burden is mainly borne by female [13].This results in the perception of female partner responsible for this issue, dragging female partner treatment and delayed male visits to infertility clinic. In the present study we noticed an average time of 6.8 years post marriage to the andrology clinic visit. A couple of important reasons identified were treatment from nonandrologist doctors that's 54\% (General practitioners, psychologist, dermatologist and general surgeons). A high proportion of delayed presentation to andrology clinic is attributed to the treatment of male partner by the gynecologists $(10 \%)$, who offer only medical treatment even for cases which later on underwent some sort of surgical procedure. Our patients still have a lack of proper information regarding infertility treatment and a large number patients $(29 \%)$ receiving treatment for years from quacks and hakims without any proper work up, known diagnosis and treatment facility. The cultural and social barriers in part of patients to expose their status of infertility resulted in $6.6 \%$ of males to delay andrology visit. 
American Journal of Health, Medicine and Nursing Practice

ISSN 2520-4017 (Online)

Vol.6, Issue 6, pp 8 - 14, 2021

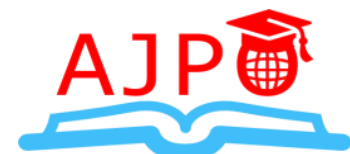

WWW.ajpojournals.org

NOA is the main diagnosis made in patients of azoospermia. We had diagnosis of NOA in $85.5 \%$, while OA and CBAVD combined accounted for $14.5 \%$. According to Jungwirth et al, OA accounts for $15-20 \%$ of cases of azoospermia [14]. Masterson et al, narrated that NOA by either primary or secondary testicular failure occurs in $60 \%$ and OA caused by anatomical obstruction in $40 \%$ of cases [15]. Basukarno et al, in their study identified $66.7 \%$ and $33.3 \%$ of patients belongs to OA and NOA respectively [16]. Liu et al, conducted a study in 2017 which showed NOA in 57.5\% and OA in $42.5 \%$ [17]. Overall the NOA is found predominantly with some studies identifying it in as high as $93 \%$ of azoospermic patients [18].

Varicocele was found in $22.8 \%$ of infertile men. In the study by E Chung prevalence of varicocele was in $25 \%$ of patients having abnormal semen parameters [19]. Gorelick et al found varicocele in $35 \%$ of primary infertility and $81 \%$ of secondary infertility cases [20]. There is association of varicocele with male infertility, the exact mechanism of which is still unknown. Therefore other issues remains to be evaluated like age, occupational risk factors and oxidative stress. Varicocele affects semen parameters in the form of count, motility, morphology and genetic material of sperm [21].

The problems we face here in the form of willingness, availability and affordability makes the treatment of male infertility a real challenge. Among male not willing for treatment the majority (47.3\%) were those counseled for ART. This can be explained in this part of the word in terms of religious and psychosocial perspective. Here still the ART is considered a controversial, objectionable modality and the common saying is that leave further fatherhood on the nature. ART is not available even in this only andrology clinic at tertiary care hospital of the province which results in the un-availability of this treatment as the sole option in $23 \%$ of male patients. Which means we lose a quarter of patients to be helped. Subsequently these patients avail the empirical treatment from the quacks and hakims with a lot of financial and psychological burden on the couple with poor outcome.

The current advances in the form of appropriate medical and microsurgical procedures in the andrology set up made the infertility treatment from dream to reality. The MSV and vasovasostomy/vasoepididmostomy are the treatment options provided in this government facility, with no issue of affordability. Apart from this the cost of medical treatment and specifically the ART was a main concern which results in the discontinuation or delaying the treatment. This could be the dilemma in the poor countries which further results in the couple separation and psychological stress. Because of lack of social security system those with no sibling for their care are vulnerable to negligence and domestic violence.

\section{Conclusion}

Even in the $21^{\text {st }}$ century the developing countries face a lot of challenges in dealing the infertile men. The unavailability of the resources, problems with counselling for infertility treatment and affording these costly treatment modalities are a number of common problems faced by the andrologist. The recent advances in the provision of proper medical treatment and microsurgical procedures which are made available resulted in a large proportion of these patients treated. 
American Journal of Health, Medicine and Nursing Practice

ISSN 2520-4017 (Online)

Vol.6, Issue 6, pp $8-14,2021$

$\underline{\text { www.ajpojournals.org }}$

\section{References}

1. Evers JL (2002) Female subfertility. Lancet 360,151-159.

2. Thonneau, P., Marchand, S., Tallec, A., Ferial, M. L., Ducot, B., Lansac, J., ... \& Spira, A. (1991). Incidence and main causes of infertility in a resident population (1 850 000) of three French regions (1988-1989). Human reproduction, 6(6), 811-816.

3. Sharlip ID, Jarow JP, Belker AM, Lipshultz LI, Sigman M, Thomas AJ, et al. Best practice policies for male subfertility. Fertil Steril. 2002;77:873-82.

4. Agarwal, A., Mulgund, A., Hamada, A., \& Chyatte, M. R. (2015). A unique view on male infertility around the globe. Reproductive biology and endocrinology, 13(1), 1-9.

5. Gerrits T. Social and cultural aspects of subfertility in Mozambique. Patient Educ Counsel 1997;31:39-48.

6. Fahami, F., Quchani, S. H., Ehsanpour, S., \& Boroujeni, A. Z. (2010). Lived experience of infertile men with male infertility cause. Iranian journal of nursing and midwifery research, 15(Supp11), 265.

7. Lee, H. S., \& Seo, J. T. (2012). Advances in surgical treatment of male infertility. The world journal of men's health, 30(2), 108-113.

8. Ombelet, W., Cooke, I., Dyer, S., Serour, G., \& Devroey, P. (2008). Infertility and the provision of infertility medical services in developing countries. Human reproduction update, 14(6), 605-621.

9. Gul, S., Ashraf, H., Khawar, O., \& Moid, M. (2019). Prevalence and Preventive Measures of Infertility in Male by Kruger's Criteria, a Randomized Study in Private and Government Health Care Hospitals. Bangladesh Journal of Medical Science, 18(1), 94-99.

10. Öztekin, Ü., Caniklioğlu, M., Sarı, S., Selmi, V., Gürel, A., \& Işıkay, L. (2019). Evaluation of male infertility prevalence with clinical outcomes in middle Anatolian region. Cureus, 11(7).

11. Eric, S. N., Justine, B., \& Jean, N. P. (2016). Prevalence of the Infertility Among Couples in Ouagadougou (Burkina Faso): a Population-based Survey. The Open Public Health Journal, 9(1).

12. Deshpande, P. S., \& Gupta, A. S. (2019). Causes and prevalence of factors causing infertility in a public health facility. Journal of human reproductive sciences, 12(4), 287.

13. Sharma KA, Yadav A, Sridhar C, et al. Reducing the waiting time to initiation of infertility treatment at a tertiary care centre in India. BMJ Open Quality 2020;9:e000975. doi:10.1136/ bmjoq-2020-000975.

14. Jungwirth, A., Giwercman, A., Tournaye, H., Diemer, T., Kopa, Z., Dohle, G., ... \& EAU Working Group on Male Infertility. (2012). European Association of Urology guidelines on Male Infertility: the 2012 update. European urology, 62(2), 324-332.

15. Masterson, J. M., \& Ramasamy, R. (2018). Case-Azoospermia with bilateral varicocele and normal folliclestimulating hormone. Canadian Urological Association Journal, 12(11), E486. 
American Journal of Health, Medicine and Nursing Practice

ISSN 2520-4017 (Online)

Vol.6, Issue 6, pp $8-14,2021$

www.ajpojournals.org

16. Basukarno, A., Birowo, P., \& Rasyid, N. (2016). Cut-off Value of Testosterone and FSH Level in Patient with Azoospermia. KnE Medicine, 145-152.

17. Liu, J., Wang, Z., Li, M., Zhou, M., \& Zhan, W. (2017). Differential diagnostic value of obstructive and nonobstructive azoospermia by scrotal ultrasound. Ultrasound quarterly, 33(4), 272-275.

18. Fogle, R. H., Steiner, A. Z., Marshall, F. E., \& Sokol, R. Z. (2006). Etiology of azoospermia in a large nonreferral inner-city population. Fertility and sterility, 86(1), 197-199.

19. Chung, E. (2014). Varicocele and male infertility: Evidence in the era of assisted reproductive technology. Reproductive System and Sexual Disorders, e114-e114.

20. Gorelick, J. I., \& Goldstein, M. (1993). Loss of fertility in men with varicocele. Fertility and sterility, 59(3), 613-616.

21. Zhang, Y., Ma, T., Su, Z., Ye, M., Tian, H., Li, J., \& Liu, J. (2017). Varicoceles affect semen quality of infertile men in Southern China: A cross-sectional study of 5447

cases. Medicine, 96(31). 